\title{
On the spontaneous beauty of cities: neither design nor chaos
}

\author{
Stefano Cozzolino ${ }^{1}$
}

Accepted: 3 August 2021 / Published online: 18 August 2021

(c) The Author(s) 2021

\begin{abstract}
A clear bridge connecting the theory of spontaneous order and the issue of beauty in and for cities has not yet been developed. After a general exploration of the concept of beauty, this article builds an alternative idea of beauty, namely, beauty as spontaneity. In particular, it argues that beauty in the urban realm greatly depends on forms and orders that can hardly be comprehensively designed but rather emerge as the result of the freedom granted to multiple urban agents to express themselves in space. In this article the works of Jacobs and Romano are analysed and explored. Starting from some of their main ideas, the paper suggests certain planning and design tactics to nurture this kind of beauty and provides some essential ethical principles.
\end{abstract}

Keywords Beauty $\cdot$ Spontaneity $\cdot$ Self-organization $\cdot$ Aesthetic $\cdot$ Action

Art is not remote from common life after all. In its highest manifestations art is life at its best.

(Carleton Noyes 1907)

\section{Introduction}

What types of beauty do cities express? When can a city, or parts of it, be defined and experienced as beautiful? This article uses the works of Jane Jacobs and Marco Romano to explore these questions, though it is not limited to an analysis of their ideas; it aims at consolidating an alternative idea of beauty based on the theory of spontaneous order. The idea of beauty discussed here can be defined as alternative because it does not refer to classical ideas of beauty focused on well-designed objects and/or areas. Conversely, the area of interest here is the idea of beauty as the evolving and emergent result of multiple, non-centrally coordinated free actions of urban agents, especially when they are relatively small and densely concentrated in space. Moreover, the idea of beauty as spontaneity is generally underestimated, if not

Stefano Cozzolino

stefano.cozzolino@ils-research.de

1 ILS - Research Institute for Regional and Urban Development, Brüderweg 22-24, 44135 Dortmund, Germany almost entirely missing, in the literature. The main thesis is that a relevant part of what is usually considered as aesthetically valuable in cities is not - and cannot always be - the product of rational, comprehensive designs but instead is the freedom and the possibility of individuals to express themselves in the urban fabric.

This article first discusses the classic idea of beauty, its relevance, and its main concepts. It then presents two types of order, grown (i.e. spontaneous) order and made (i.e. designed) order, as two different ways in which beauty can eventually be generated. It then goes on to analyse the works of Jane Jacobs and Marco Romano and clarifies potential misunderstandings. Some final remarks on a conceptualisation of beauty as spontaneity, as well as certain fundamental ethical principles of the study, are then explained.

It is important to note that a clear bridge connecting spontaneous order theories and the topic of beauty in and for cities has not yet been developed to date, which is why this article is urgently needed. However, it also essential to stress that all aspects of the idea of spontaneous forms of beauty cannot be discussed in a single paper. For example, this paper does not extensively deal with the analysis of people's actual aesthetical perceptions of largely spontaneous or largely designed places, nor does it look at key planning aspects, such as property rights and regulative frameworks that favour the emergence of spontaneous social-spatial configurations, in depth (on this topic see Cozzolino and Moroni 2021; Moroni and Cozzolino 2019). The general hope is 
that this article will lead to a more consistent understanding of the concept of beauty as spontaneity, which will, in turn, lead to further integration into the literature of research fields such as urban design, architecture, and urban planning, as well as urban justice and ethics. Indeed, the paper will demonstrate that the concepts of beauty, justice, and ethics are strictly connected.

\section{Beauty, concepts, and different geneses}

\section{The concept of beauty and its application}

The concept of beauty is employed in numerous fields and aspects of life, from music to paintings, from literature to theatre, from architecture to landscapes, from human bodies to machines. In dealing with the universal meaning of beauty, Umberto Eco (2004) maintains that beautiful is an adjective that is used to indicate something that we like, something that conforms to some ideal principles of 'the good'. According to Eco, however, what is considered beautiful may vary in time and geography depending on epochs and cultures. The concept of beauty, then, also depends on the ways in which individuals see and appreciate the world. Indeed, beauty is a sensory enjoyment based on individual cognitive understanding. ${ }^{1}$ Kant (1790/2009) interprets this concept as a subjective universal judgement, meaning that, even though the judgement is subjective, other people will agree with it (see also Chiodo 2019). In particular, he distinguishes between free beauty and adherent beauty; while the first judgement is made without having one determinate concept of beauty in mind, the latter is adherent to a specific and intersubjective shared idea of beauty. In short, beauty is a concept that implies both subjective and intersubjective (i.e. collective) understandings.

To be sure, there are many relevant definitions of beauty. Nevertheless, one must acknowledge that, since the time of the ancient Greeks, the classical concept of beauty has been associated with certain principles of order and harmony (the good) in contrast with an otherwise chaotic world (the bad). This contrast has pervaded worldwide our imagery ever since. For example, it is no coincidence that in art, hell (i.e., the $b a d$ ) is represented in a chaotic, disorderly, and even dreadful way, while heaven (i.e., the good) has always evoked a sense of order and harmony, an ideal of beauty to which humans must aspire. In this sense, beautiful and ugly, like good and bad, are strictly connected dichotomies. Without the good and the beautiful, the bad and the ugly cannot exist. This dichotomy was expressed indelibly in the

\footnotetext{
${ }_{1}$ Relevant and sophisticated studies on cognition have been developed by Juval Portugali (e.g., 2016).
}

fourteenth century by Ambrogio Lorenzetti in The Allegory of the Good and Bad Government. In three frescoes, the Italian painter shows the social and spatial effects of well and poorly administered cities; on the one hand, an orderly, harmonious, peaceful, and even prosperous city; on the other, a badly administered city dominated by disorder, violence, and ruins of all kinds, its surrounding lands left uncultivated and its buildings decaying. Similarly, Renaissance paintings that deal with the representation of the ideal city generally portray the urban fabric with regular geometries, harmonic proportions, and perfect order. The implicit characteristic of these environments is that they require the educated hands of a designer.

Although apparently antiquated, at least in terms of Western civilization, these ideals still exemplify a classic and (still) widely shared concept of beauty. This does not mean that other, even deeply different, concepts of beauty have not also developed; the point is that the idea of intentionally organizing an otherwise unfunctional and unpleasant urban environment according to certain principles of order and harmony derived from longstanding cultural backgrounds is still a dominant tradition that has enormously affected planning and city design. ${ }^{2}$

In the literature, harmony and order seem to be the two concepts that better describe the essence of beauty. For example, in Moore's analysis of different ideas of beauty (1942, p. 42), a classical, formalistic definition of beauty is envisioned in terms of order and harmony possessing unity in variety, that is, a variety of details combined into a united general effect: "Variety without unity is confusing, and unity without variety is monotonous and uninteresting." The author also argues that, "order is the principle which brings unity of general effect out of what would otherwise be a confused jumble of details, and produces a harmonious and beautiful whole". In short, beauty can be most appreciated when a variety of details and elements are so related to one another that a general unity of the whole exists.

Cities are not exempt from the application of the concept of beauty; urban design has been guided and permeated by this notion throughout the ages. Following Akkerman (2000, p. 272), "Harmony, and the allied concepts of order [...] became pivotal in the history of later urban thought." Several authors were (and still are) in search of principles of good urban design and urban forms capable of generating beauty. In this regard, Lynch (1960), probably the most influential thinker of the last century in this field, suggested that the central idea of good urban design should be spatial legibility, that is, a structural organization of space

\footnotetext{
${ }^{2}$ For more on this topic, see Bentley (2002) and Keane and Jones (2020).
} 
capable of bringing clarity and coherent patterns to the built environment.

Legibility is, for Lynch as well as the vast majority of other theorists, a fundamental aspect of beautiful cities. This element underscores the importance of having and creating a recognizable order in an otherwise illegible and chaotic environment. Although his ideas have been accepted and developed by many urban design and planning theorists since then, it is worth noting that barely legible cities are often appreciated as well (Akbar 1988; Kostof 1991; Habraken 1998; Mehaffy 2007; Marshall 2009; Hakim 2014; Dovey and Pafka 2015; Kelso et al. 2016; Ikeda 2017; Wohl 2017). As Taylor points out (2009, pp. 198-199), "almost everybody agrees that old Venice is one of the most beautiful cities in the world, and yet it is also as good an example [...] of an illegible townscape." The main point is that, "a central aspect of this aesthetic quality of a townscape will be the extent to which we find a townscape sensually enjoyable to see, hear, smell, and touch." The position maintained by Taylor is agreeable to a large extent. Naples is another example; its 'chaotic' beauty is often described in the literature. Walter Benjamin and Asja Lacis (1925, pp. 163-173) describe it as an unceasing sequence of surprises within a highly complex and porous built environment, the stage of popular improvisation and representation: "Buildings are [...] all divided into innumerable, simultaneously animated theatres. Balcony, courtyard, window, gateway, staircase, roof are at the same time stage and boxes. Even the most wretched pauper is sovereign in the dim, dual awareness of participating, in all his destitution, in one of the pictures of Neapolitan street life." In a similar vein, in his famous Italian Journey 1786-1788, Goethe (1982, p. 189) writes, "I won't say another word about the beauties of the city and its situation, which have been described and praised so often [...]. Naples is a paradise; everyone lives in a state of intoxicated self-forgetfulness, myself included" (ibid., 207).

In short, cities do not achieve aesthetic appreciation only for their spatial legibility or, to put it differently, for those elements that are well-designed and intentionally organised by talented architects and planners; in fact, there are other hardly controllable, social-spatial factors as well. NorbergSchulz (1979) referred to these elements as 'character' and 'sense or spirit of place', elements that often cannot be visualized (see also Sepe and Pitt 2014). Alexander (2003, p. 15) spoke of 'wholeness', 'adaptational complexity', and 'quality without a name'; these factors are hardly comprehensible at a first glance but are highly appreciated both in terms of individual buildings and entire towns (see also Mehaffy 2007). The key here is the contributions and presence of multiple ordinary urban agents, not just city designers.

\section{Two types of order, two types of beauty?}

Order and harmony best describe the essence of beauty, at least in its most common and classic form. A key question, therefore, concerns how harmony and order (visual, functional, or social) can be generated in cities and therefore how beauty eventually manifests itself within the built environment. In answering this question, we will refer to theories that explore how different forms of order and harmony may emerge spontaneously in social systems. Although these theories do not explicitly address urban design, they are helpful for developing valid arguments and providing acceptable explanations. Indeed, recent works of preeminent scholars have demonstrated that the theory of spontaneous order is not valid simply to comprehend how cities, their institutions and built environments perform over time, but this discussion may be relevant for the design of these as well. ${ }^{3}$

Referring mainly to social systems, Hayek (1973, p. 35) defines order as, "A state of affairs in which a multiplicity of elements of various kinds are so related to each other that we may learn $[\ldots]$ to form correct expectations concerning the rest." Following his words, a system composed of multiple elements (social or physical) can be defined as 'ordered' if it shows certain patterns and regularities that create an interrelated whole. Although the word order is generally associated with authoritarian and hierarchical views and reminds one of concepts such as command and obedience, in practice, order can also emerge in the absence of commands or central coordination. This idea almost entirely overlaps with the Jacobsian concept of a city as a problem of organized complexity (Jacobs 1961), that is, a problem in which a large number of factors are all harmoniously interconnected into an organic whole without central coordination.

Hayek explains that two types of order exist in social systems, made order and grown order. Made order is a rationally constructed arrangement imposed upon a certain system; it is usually described as planned or designed, and is typical of man-made organizations. A classical opera, a military parade, and the production line of a car manufacturer are all forms made order. Conversely, grown order is not intentionally and rationally created by anybody, but rather emerges spontaneously from the bottom up over time. In other words, it is not the result of a top-down plan or design but the spontaneous product of multiple actions and interactions with no central coordination (Moroni et al. 2020). Although it is path-dependent, the development of grown order cannot be known in detail in advance because it is open-ended by definition. A jam session, the free flow of pedestrians in a

\footnotetext{
${ }^{3}$ See, for example, Alfasi and Portugali (2007), Buitelaar et al. (2014), Ikeda and Callahan (2014), Dovey and Pafka (2015), Wohl (2017), and Porqueddu (2018).
} 
city street, the distribution of economic activities, and the organic morphology of old towns are all examples. Whilst a made order is simple in the sense that it is humanly conceived and governed as well as easily predictable, a grown order is complex and not always easily understandable at a first glance. For example, in a unitarily designed residential neighbourhood, it will take a few minutes to understand where to go grocery shop or drink a coffee with fellow inhabitants, while in highly complex environments such as the ones of Venice and Naples, these types of discoveries are never banal.

Another difference is that the primary issue with made order is often in its implementation. Conversely, grown order cannot, strictly speaking, be implemented; it evolves progressively and incrementally over time. It is a never ending process that brings a succession of surprises and changes. Although not shaped from the top down, grown order does show its own version of regularities and patterns.

In brief, order and harmony can be generated in socialspatial systems in two different ways. The first is by means of design while the second is unintentional and spontaneous. Importantly, these two opposite forms of order are ideal and do not manifest themselves in absolute terms. More correctly, one might say that a system can be more or less spontaneous or more or less designed. Indeed, these two types of order often co-exist, as forms of spontaneous order may evolve within previously designed systems and elements (see Cozzolino 2020). Moreover, spontaneous order can also be intended as the emergent aggregation of many small and intentionally developed plans and designs (Portugali 2016).

In this regard, a made order in cities is usually easily legible, as seen in some entirely designed neighbourhoods. In Milan some examples include the neighbourhoods of the Bicocca area, Gratosoglio, Rubattino, Pompeo Leoni, and the Gallaratese, to name a few. Although some may appreciate their architecture, these areas are largely considered dull and monotonous and are often unappreciated aesthetically (this issue is discussed in more detail in the next section). ${ }^{4}$ Conversely, as Taylor (2009) rightly suggests, cities need characters, aspects, situations, and places that go beyond mere design and geometric spatial control. This means that a vast component of aesthetically enjoyable urban environments depends on shapes, expressions and dimensions that, due to their complexity, are neither easily understandable nor mechanically designable or replicable. As with Venice and Naples, this is a different kind of beauty that does not

\footnotetext{
${ }^{4}$ It is important to note that I am not claiming that these places cannot be appreciated aesthetically. Architects sometime appreciate these areas because they recognize the initial designer's aesthetic intention, and local inhabitants often develop a strong sense of attachment and belonging; this, however, cannot be considered a pure form of aesthetic appreciation.
}

refer exclusively to the shape of the built environment but rather concerns the way people and built forms interact and influence each other in a continuous process of dynamic interaction. These are all fundamental elements that create identity and characters (Sepe and Pitt 2014). This idea is central to the arguments of Marco Romano and Jane Jacobs.

\section{The contributions of Jacobs and Romano}

In this section, the works of Marco Romano and Jane Jacobs ${ }^{5}$ are analysed and compared in terms of five questions: Is the city a work of art? What is the main triggering factor of beautiful cities? How do planning and city design contribute to beauty? What is the main difficulty in planning and city design? What kind of order do Jacobs and Romano envision?

To be sure, Marco Romano and Jane Jacobs are not the only authors who write about cities in terms of the extensive (whether explicit or implicit) use of the theory of spontaneous order. The selection of these two authors is primarily due to three factors. First, Jacobs and Romano effectively address the beauty and aesthetics of cities, Romano explicitly and Jacobs mostly indirectly. Second, they complement each other; while Romano pays more attention to built forms and architecture, Jacobs places more emphasis on social and economic aspects. Third, both authors clearly defend and promote certain libertarian principles. For instance, they both stress the ideals of freedom and self-determination and the relevance of the individual rights of citizens, and they emphasize the need to decentralize power in society so that forms of 'localisms' can be effectively promoted and safeguarded. Finally, although they write about different contexts (Jacobs describes large American cities while Romano addresses traditional European ones), they adopt similar principles that are useful for clarifying the idea of beauty as spontaneity as well as certain preliminary conditions that favour its emergence.

\section{Jane Jacobs: diversity and intricacy as the main drivers of beauty}

Jacobs rarely uses the word beauty, which could be a strategic choice to distance herself from the City Beautiful movement. However, in several circumstances, she uses expressions like 'aesthetic' and 'pleasant' to describe places and urban environments that she particularly appreciates.

According to Jacobs, the mere presence of well-designed elements is insufficient for the creation of pleasant urban

\footnotetext{
5 The article refers mainly to The Death and Life of Great American Cities (Jacobs 1961) and "La cittá come opera d'arte" (Romano 2008).
} 
environments. For example, in discussing the life of city streets, she writes (1961, p. 74), "no matter of aesthetic quality $[\ldots]$ what matters are the tangible enterprises sidewalks have." In her view, radical differences and mixtures in uses, functions, and population are the primary factors for the creation of beautiful cities (ibid., 298). It is no coincidence that she appreciates neighbourhoods, such as Boston's North End, that, independently from their bad reputations within the planning and design communities, possess a high degree of intricacy and vibrancy. In this regard, she would probably agree that design can support the beauty of cities, but life is what makes them a real wonder. In her words, city design is irrelevant if it doesn't support an intricate city life: "When we deal with cities we are dealing with life at its most complex and intense. Because this is so, there is a basic aesthetic limitation on what can be done with cities: a city cannot be a work of art" (ibid., 485). In a work of art, artists have the chance to compose elements and materials as they please. Forms, harmonic appearance, order, and overall coherence are all under their direct control. A city, however, does not work in this manner. According to Jacobs, a city cannot be a work of art because, "to approach a city as if it is a larger architectural problem [...] is to make the mistake of attempting to substitute art for life" (ibid., 486). In raising this point, she emphasizes that a city is not under the control of one single actor but is rather a living organism composed of multiple, diverse individuals who actively participate in its never-ending modification and evolution. Indeed, cities offer, "a fertile ground for the plans of thousands of people" (ibid., 20). For Jacobs, the main driver of beauty in cities is a high concentration of diversity: "Cities are full of people doing different things [...]. It is the richness of human variation that gives vitality and colour to the human setting" (ibid., 72).

The kind of order envisioned by Jacobs is the complex product of an uncountable number of individuals who give rise to an emergent and interrelated whole. For Jacobs, what is often seen as disorder and chaos is instead a more sophisticated form of order, "the manifestation of the freedom of countless numbers of people that make and carry out countless plans" (ibid., 510). To see this complexity as order and not chaos takes understanding. In this regard, she argues that (ibid., pp. 223-224), "it is part of the beauty of this order that success for the mixture in itself, and success for the peculiar and specific elements of the mixture, are apt to be in harmony rather than contradiction." Although harmonious overall, this form of order is peculiar in that it is entirely composed of social, cultural, architectural, and economic variances.

Jacobs is deeply critical of top-down planning interventions. However, she believes that planning and city design can play an important role in favouring the spontaneous emergence of workable and pleasant cities by modifying or introducing certain spatial conditions. She refers to these conditions as, "the conditions that generate diversity." Her main point is that planners and city designers cannot directly create diversity; they can merely encourage its emergence: "The main responsibility of city planning and design should be to develop cities that are congenial places for this great range of unofficial plans, ideas, and opportunities to flourish" (ibid., 315). In her view, it is possible to nurture the natural emergence of diversity through certain tactics, some of which are presented as follows. First, by designing certain collective spaces, such as streets, squares, and open spaces, in such a way that these elements can effectively support dense spontaneous interactions, exchanges, and opportunities for smallness. For example, the general street structure should induce the creation of short blocks, as opposed to large ones, encourage movement and surprises by increasing the number of street intersections, and strengthen the interface between private buildings and sidewalks. Second, landmarks, whether architectural or functional, may be introduced as a way of clarifying order and dignifying the diversity of the area by introducing hierarchical structure to the built environment (ibid., 500). Finally, rigid and unnecessary legal prescriptions that over-limit micro-entrepreneurialism and organic adjustments in the built environment should be abandoned. ${ }^{6}$ From this perspective, no uses should be prevented in cities as long as they do not effectively harm neighbours. For example, zoning should not prescribe the uses of certain locations in detail but rather favour experimentation, trial and error, and the development of new uses while preventing nuisances.

For Jacobs, the main problems caused by planning and city design do not necessarily concern top-down designs per se, but rather over-intervention. The real problem is that, "the principles of bringing order by repression of all plans but the planners' have been easily extended to all manner of city functions, until today a land-use master plan" (ibid., 34).

\section{Romano: beauty as individual and collective self-expression}

Marco Romano deals explicitly with the issue of beauty. In his book Liberi di Costruire ("Free to build"), published in 2013, he takes a distinguishable libertarian position, which Jacobs never does. His writings offer a unique perspective on the interrelation between architecture, urban design, justice, and aesthetics.

\footnotetext{
${ }^{6}$ This statement further illuminates her position: "Frequent streets are not an end in themselves. They are a means towards an end. If that end - generating diversity and catalysing the plans of many people besides planners - is thwarted by too repressive zoning [...] nothing significant can be accomplished by short blocks," $(1961,243)$.
} 
Romano maintains that an artefact must be designed with the specific intention of creating a work of art in mind to be considered such. Nevertheless, the concept of beauty (and ugliness) is often incorrectly used to describe things of the world that do not meet this criterion, like sunsets, landscapes, and, more importantly, cities as a whole. The problem is that considering a whole city to be a work of art results in some difficulties in that a city is made up of many diverse artefacts with their own specific aesthetic expression. Although these artefacts might eventually create a harmonious whole, this cannot be considered as a unitary element (2008, pp. 28-29). Therefore, a city may look like a work of art if its configuration gives rise to a coherent whole, but it cannot, strictly speaking, be thought of as one because it lacks specific aesthetic intentionality.

Romano also emphasizes the importance of the distinction between unintentionally generated collective themes emerging from the actions of separate individuals, such as certain local construction types, spontaneous morphological grammar, and recurrent styles/elements and their combination, and intentionally designed collective themes developed by the city, like the design of monumental squares, boulevards, and municipal buildings. Although deeply different in their genesis, these two types of aesthetics co-exist. According to Romano, however, the main driver of beauty in cities is the freedom of citizens to express themselves and their aesthetic wills within the built environment. Romano, especially in the case of traditional built environments, describes this as a process of genuine competition among different households who, according to their economic possibilities and aesthetic preferences, express their status through the facades of buildings. This process is relevant not only at the individual level because it pays back the investments of households but also, more importantly, for the city as a whole. In fact, by pursuing their individual aesthetic aspirations, households are (often unconsciously) contributing to the overall beauty of the city (ibid., 95). Romano argues that this is how the beauty of historical cities, such as Venice, Amsterdam, and Bruges, has emerged over the centuries. Importantly, although each household acts individually, the presence of habits, social norms, and customs, as well as certain legally binding codes create an institutional framework that guarantees the formation of an overall sense of harmony.

Although the multiple small actions of households are considered to be the main driver of beauty by Romano, he also maintains that urban planning and design can play a pivotal role in the creation of beautiful cities, provided that their role is confined to the shaping of certain collective elements. These elements include streets and squares, monuments, railway stations, cultural centres, bridges, schools, hospitals, and parks. Just as single households express their aesthetic will in the construction of buildings' facades, different cities may represent themselves in the design of collective spaces.
Different from the spontaneous beauty emerging from the multiple actions of individual households, such collective elements can effectively be intended as works of art. In fact, as in any work of art, there is a client (the city) and one specific designer (for example, one architect) who intentionally express a particular idea of beauty. As Romano maintains, it is a given that, in cities, especially traditional European cities, certain collective elements are or should be proper works of art.

According to Romano, urban design and architecture, especially on a large scale, can also have devastating effects. As he points out, this threat derives from a profound cultural change in the twentieth century and the consolidation of certain ideas of the modern movement. One is the idea of the neighbourhood unit and total design; another is the increase in state intervention through land-use regulation and building codes. According to Romano, these relevant changes have turned the traditional development process, which has characterized the incremental and largely spontaneous growth of cities for centuries, into a more standardized process. ${ }^{7}$ Additionally, the contemporary and largely held belief that a settlement can become more beautiful if it is designed unitarily by one archistar (leaving almost no room for individual expression and unexpected adaptions) is debatable, to say the least. The case of the Bicocca district in Milan, as discussed by Romano, is a perfect example. This area, Romano explains, appears dull because its buildings do not reflect the diverse inclinations of individual taste but exclusively those of the designer (ibid., 143). Therefore, the absence of individual aesthetic expression in the built environment gives rise to contexts that lack what Romano refers to as the fundamental dignity of the place. The often peripheral neighbourhood units built in recent decades are typical examples of this problem. ${ }^{8}$ According to Romano, the lack of freedom and space for individual expression in these areas underscore second-ranking citizenship (ibid., 69).

Finally, Romano discusses two main types of order that overlap with the two discussed by Hayek. He asserts that both types of order, i.e., made/design and grown/spontaneous, play an important role in cities. While a made order can be used to try to generate intentional beauty (in the case of certain collective spaces, for instance), grown order is essential for guaranteeing individual expression in space and is crucial for avoiding aesthetic uniformity and enabling the

\footnotetext{
7 To give an example, if today's designers tried to recreate the same physical patterns of the traditional city, they would be largely prevented by the presence of numerous prescriptions regarding, for example, minimum road widths, minimum distances between buildings, minimum parking lots, minimum spaces for green areas, and other standards that reduce the adaptive capacity of the built environment.

8 This is extensively discussed in Cozzolino (2020).
} 
creation of places with strong character and dignity of the place.

\section{Toward a conceptualization of beauty as spontaneity}

Although it has not been thoroughly explored yet, the concept of beauty as spontaneity is both possible and consistent. The previously discussed authors not only provide some explanations as to why spontaneous beauty is relevant, they also offer some ways to facilitate its emergence. Indeed, spontaneous beauty cannot be designed directly; it evolves unintentionally with the passage of time as a result of multiple actions. This is a process that, step-by-step, can eventually lead to coherent and beautiful organic results (Mehaffy 2007 , p. 57). However, not everything spontaneous or emergent is beautiful. Certain spontaneous patterns and configurations might be indeed ugly by most accounts if a set of intersubjective mutual conditions that guarantee harmony and order are not respected. For example, an overcrowded settlement without basic infrastructures or an ensemble of charming buildings that is difficult to walk through due to the lack of passages would hardly be experienced as beautiful. Thus, a more tenable position is that spontaneous order, and the apparent "chaos" that typically accompanies it, is consistent with beauty if it generates complementarity among diversity and a sense of an organic whole. Moreover, it is important to keep in mind that, as with other concepts of beauty, beauty as spontaneity is an ideal that envisions certain specific ideas of the good. This type of beauty does not prioritize any specific urban form nor does it believe that harmony and order are merely geometrical and physical problems. Or, to put it differently, the shape of the built environment is not an end in itself but is instead a means to nurture the multiple actions and interactions of individuals; that is, life.

From this perspective, and following the contributions of Romano and Jacobs, three minimal pre-conditions to embrace beauty as spontaneity seem necessary:

I. The presence of adequate space for creative action and individual expression. This principle does not only guarantee variety and diversity in the urban system, it recognizes individual dignity and the right to express oneself as essential values. As Chiodo (2019, p. 35) aptly puts it, "It is beautiful the space which represent who we are." It is important to note that diversity can manifest in different ways. In social terms, for example, it represents the presence of people of different statuses, cultural backgrounds, and ages. From an economic perspective, it means the mixed existence of different uses and activities of different scales and relevance that are created by urban agents in response to market processes. From an architectonic perspective, diversity might mean buildings of different epochs, qualities, and styles, among other things. These factors cannot be created directly via top-down design; they emerge and are trigged by favourable conditions.

II. A real process of spatial democratization; that is, the participation of the highest number of individuals possible in the creation and adaptation of the urban system. This means increasing the number of people that are able to act independently and express themselves in space. Note that the term participation here does not necessarily mean the involvement of people in decision-making and public policies but rather "direct action".

III. The presence of an institutional framework that protects the collective dimension of cities and favours the emergence of unexpected actions and interactions. This means, for example, introducing certain public rules on private spaces to increase the degree of freedom for urban agents while also protecting them from the emergence of negative externalities. It also means providing and maintaining certain collectively relevant spaces and services that form the urban skeleton on which future actions and interactions will continuously modify the built and the social environment. ${ }^{9}$

It is worth re-discussing the fact that the appreciation of spontaneous beauty does not mean that forms of designed order in cities are irrelevant or cannot generate aesthetic value. If well-designed, certain elements, such as streets, squares, or parks, are not only essential for the functioning of cities but can also generate breath-taking beauty. For example, in revisiting the case of Naples, for example, it is possible to imagine that the bustling and spontaneous beauty of the city, so well described by Goethe, Benjamin, and Lacis, could not be appreciated to the same degree without the existence of its opposite, that is, its iconic and monumental collective spaces and elements. Such designed elements not only introduce a different type of order to the city, they can also be considered true works of art of collective representation. The vast, harmonious, and majestic Piazza del Plescito, to which some of the city's most popular, vital, and fascinating neighbourhoods cling, or the seafront of Via Caracciolo, which allows citizens and visitors alike to enjoy the view of the spectacular gulf, are two examples of elements of this kind. In cities, these two types of beauty effectively co-exist;

\footnotetext{
${ }^{9}$ Similarly, Wohl (2017) speaks of a proscriptive approach to urban design.
} 
therefore, emphasizing the relevance of spontaneous beauty does not negate the relevance of designed beauty.

In short, although beauty as spontaneity implies an emergence by means of a purely self-organizing process and beauty as design implies the exact opposite, these two forms should not be seen in contraposition but as complementary; they are more intensively correlated than can be imaged. In fact, spontaneously emerging forms of beauty can continuously emerge within intentionally created top-down designs and spatial frameworks (Marshall 2009; Kelso et al. 2016). This complementarity works as a trade-off between design and spontaneity in the urban realm (Ikeda 2017). Cases of total spontaneity are seen in informal settlements all around the world, while examples of total design include certain New Towns built after WWII and standard Sovietera neighbourhoods. In most cases, however, cities are neither totally designed nor totally spontaneous. Great cities developed through forms of plot-based urbanism, such as New York and Barcelona, where the structure of the streets was designed from the top-down and the fine-grain of city blocks was left open to spontaneous processes, are perfect examples (Porta and Romice 2014; Porta et al. 2016). However, many other, apparently less significant cases, can be taken into consideration as well. For instance, certain relatively small Sicilian cities, such as Noto, Grammichele, Pachino, and Avola are good examples in which it is possible to make a clear distinction between designed collective elements (primarily streets and squares) and the ample space left for the spontaneous expressions of households. Here, this freedom of expression extends from the appearance of single buildings to privately customized and richly coloured public sidewalks where citizens can creatively express their aesthetic wills. Hence, the ways in which forms of designed and spontaneous order (and beauty) are combined is more complex than a simple dichotomy. Above all, the presence of one kind of beauty does not preclude the presence of the other, especially if we analysed the urban environment in a multi-scalar way.

The fundamental role played by free actions of urban agents in the creation of beauty needs to be better specified and addressed. Action, as maintained also by Jacobs and Romano, the main driver of what is here called spontaneous beauty, can be defined as the intentional, creative plans and designs of urban agents (especially 'small' agents such as households, shopkeepers, associations, etc.) who are in the position to express their aesthetic will in the built environment. These actions have an important meaning for the built environment. They represent the ordinary manifestation of individuals' preferences and choices as well as the concrete possibility for individuals to identify themselves in space. In addition to generating diversity as a natural result, when such actions are highly concentrated in space, they give rise to intricate urban areas and a continuous flow of novelties: two relevant factors for the emergence of urban identities and the unique spirit of place. From this perspective, the issue of property rights, and especially how property is distributed in space (Bobkova et al. 2019), cannot but play a crucial role in the discussion. In fact, property in the built environment directly involves the question of who can make decisions about certain spatial changes and adaptions, and act accordingly (Kropf 2018). Hence, a key condition for the emergence of spontaneous beauty is several property (Hayek 1988). In this situation, power of action and control is dispersed among the "several - meaning 'diverse, many, numerous, distinct, particular, or separate' - persons and associations that comprise a society, rather than being reposed in a monolithic centralized institution" (Barnett 1998 , p. 65). In this regard, it is important to stress the importance of (several) private property. In fact, contrary to the case of public property where the use of any object comes to be defined politically in the name of the public interest, in the case of private property, urban agents should be able to freely express their independent aesthetic wills (within, of course, certain mutual regulative constraints).

Great emphasis has been put on the importance of individual actions, but spontaneous built environments (and spontaneous forms of beauty) are not necessarily the result of an individualistic or atomistic society per se. First of all, an action does not necessarily need to be intended as exclusively individual; it can also be undertaken by a group of individuals acting in collaboration. Secondly, an action is always a choice happening in real time and space; it is therefore bound by contextual, intersubjective local conditions (such as habits, cultures, market circumstances, etc.) that constrain what an urban agent can do and how it can be done (Moroni and Cozzolino 2020). This issue, however, is less important in the scope of this article. What truly matters here is that spontaneous beauty can only emerge over time by urban agents acting, interacting, and expressing themselves creatively in space. In this regard, the acts of moulding, transforming, and adapting the urban fabric and its uses are all relevant. This happens, for example, when households change the appearance of their building-façade, when urban agents build a new building or renovate an existing one, when the use of a ground floor changes from residential to commercial, or when a previously closed private courtyard opens up to accommodate public activities. It also occurs when a cooperative or an association adds new elements to a commonly owned garden, for example. In a cumulative way, these kinds of (ordinary and local) actions not only continuously shape and reshape the built environment, but also give it the capacity to evolve over time. These actions are a window of opportunity and allow people to represent themselves in space so that the built environment becomes dignified by a sense of real democracy and self-representation (Brand 1995; Habraken 1998). 
An important analytical point needs to be addressed concerning the two different ways in which action exists in relation to beautiful built environments. The first way involves built environments that are the result of the stratification of multiple free actions over time; examples include the forms of urbanism typical of traditional Mediterranean (Hakim 2014) and Islamic settlements (Akbar 1988), ${ }^{10}$ those urban areas that are generally referred to as spontaneous, emergent, or organic. The second concerns the flexible space that a certain built environment provides for future actions and adaptations. These areas can be referred to as adaptable, flexible or open configurations. Whilst the first case represents the process behind the formation of complex urban shapes, the second represents the (present) propensity of settlements to host new adaptions and unexpected changes. These two levels sometimes are co-present in a specific settlement (for example in the case of spontaneously generated areas that offer flexible space for further adaptions) and other times they do not (as in the case of spontaneously generated areas now under a regime of preservation; Venice, for example).

Finally, and inevitably, planners and designers who want to embrace these ideas must embrace forms of radical pluralism and tolerance (see Basta and Moroni 2013). This requires embracing a completely different kind of approach in terms of both regulating and designing the evolution of cities, an approach that places emphasis primarily not so much on final end-states but, mainly, on the (designed) framework within which multiple, emergent scenarios can eventually evolve over time.

\section{Conclusion}

To date, a clear bridge connecting the theory of spontaneous order and the issue of beauty in and for cities has not yet been developed. This is the main reason behind this study. The hope, however, is that many others works will follow.

Freedom and space for individual aesthetic expression is essential to the creation of beauty in cities for two main reasons. First of all, at the individual level, freedom guarantees fundamental factors, such as self-determination and individual dignity; that is, the right to express. Secondly, freedom has instrumental and systemic value for the city as a whole. Indeed, the possibility for several urban agents to act may generate beauty and evolving complex characters in cities that are unobtainable by means of central coordination and extended control. Following Chiodo (2019, p. 35), "Beauty should not be a luxury for the space of a few individuals, but the norm for the space of any individual." From this perspective, the concentration or distribution of property

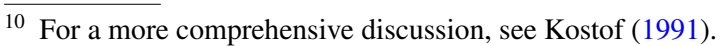

rights highly influence the spontaneous propensity of cities. A city open to the formation of highly intricate spontaneous orders is indeed one in which power of action is dispersed into the hands of many urban agents. This does not necessarily mean that public policies must fight large urban agents or large urban scale developments in themselves. Instead, they should create conditions in which small, less powerful agents can also participate in the system. This can be done in practice by creating opportunities for smallness, by means of planning rules and architectures that favour small actions and continuous adjustments as well as the design of highly permeable and porous urban structures capable of stimulating social interaction instead of neglecting it. From this perspective, the scope of planning and design interventions should involve distributing and expanding opportunities for individual and social expression throughout the city.

Funding Open Access funding enabled and organized by Projekt DEAL.

Open Access This article is licensed under a Creative Commons Attribution 4.0 International License, which permits use, sharing, adaptation, distribution and reproduction in any medium or format, as long as you give appropriate credit to the original author(s) and the source, provide a link to the Creative Commons licence, and indicate if changes were made. The images or other third party material in this article are included in the article's Creative Commons licence, unless indicated otherwise in a credit line to the material. If material is not included in the article's Creative Commons licence and your intended use is not permitted by statutory regulation or exceeds the permitted use, you will need to obtain permission directly from the copyright holder. To view a copy of this licence, visit http://creativecommons.org/licenses/by/4.0/.

\section{References}

Akbar, J. 1988. Crisis in the Built Environment. Singapore: Concept Media Pte Ltd.

Alexander, C. 2003. New Concepts in Complexity Theory Arising from Studies in Architecture: An Overview of the Four Books of The Nature of Order with Emphasis on the Scientific Problems which Are Raised. Katarxis No. 3.

Alfasi, N., and J. Portugali. 2007. Planning Rules for a Self-Planned City. Planning Theory 6 (2): 164-182.

Akkerman, A. 2000. Harmonies of Urban Design and Discords of City-Form: Urban Aesthetics in the Rise of Western Civilization. Journal of Urban Design 5 (3): 267-290.

Barnett, R. 1998. The Structure of Liberty. Oxford: Oxford University Press.

Basta, C., and S. Moroni. 2013. Ethics, Design and Planning of the Built Environment. Dordrecht: Springer.

Benjamin, W., and A. Lacis. 1925. Naples. In Reflections: Essays, Aphorisms, Autobiographical Writings, ed. P. Demetz, 163-173. New York: Houghton Mifflin Harcourt.

Bentley, I. 2002. Urban Designers as Artists. Urban Design International 7 (3-4): 143-152.

Bobkova, E., L. Marcus, M. Berghauser Pont, I. Stavroulaki, and D. Bolin. 2019. Structure of Plot Systems and Economic Activity in Cities: Linking Plot Types to Retail and Food Services in London, Amsterdam and Stockholm. Urban Science 3 (3): 66. 
Brand, S. 1995. How Buildings Tearn: What Happens After They're Built. London: Penguin.

Buitelaar, E., M. Galle, and N. Sorel. 2014. The Public Planning of Private Planning: An Analysis of Controlled Spontaneity in the Netherlands. In Cities and Private Planning Property Rights, Entrepreneurship and Transaction Costs, ed. D.E. Andersson and S. Moroni. Cheltenham: Edward Elgar.

Chiodo, S. 2019. Judging the Value of Beauty: From Aesthetics to Ethics. Rivista SIEV Valori e Valutazioni 23: 31-36.

Cozzolino, S. 2020. The (anti) Adaptive Neighbourhoods Embracing Complexity and Distribution of Design Control in the Ordinary Built Environment. Environment and Planning B 47 (2): 203-219. https://doi.org/10.1177/2399808319857451.

Cozzolino, S., and S. Moroni. 2021. Multiple Agents and Self-Organisation in Complex Cities: The Crucial Role of Several Property. Land Use Planning 103: 2.

Cozzolino, S., J. Polívka, R. Fox-Kämper, M. Reimer, and O. Kummel. 2020. What is Urban Design? A Proposal for a Common Understanding. Journal of Urban Design 25 (1): 35-49.

Dovey, K., and E. Pafka. 2016. The Science of Urban Design? Urban Design International 21 (1): 1-10.

Eco, U. 2004. Storia della bellezza. Milano: Bompiani.

Goethe J. W. (1982/1996). Italian Journey (1786-1788). London: Penguin Books.

Habraken, N.J. 1998. The Structure of the Ordinary: Form and Control in the Built Environment. Cambridge: MIT.

Hayek, F.A. 1973. Law, Legislation and Liberty: A New Statement of the Liberal Principles of Justice and Political Economy. Chicago: University of Chicago Press.

Hayek, F.A. 1988. The Fatal Conceit. London: Routledge.

Hakim, B.S. 2014. Mediterranean Urbanism. Historic Urban/Building Rules and Processes. Berlin: Springer.

Ikeda, S. 2017. The City Cannot Be a Work of Art. Cosmos Taxis 4 (2): 79-86.

Ikeda, S., and G. Callahan. 2014. Jane Jacobs' Critique of Rationalism in Urban Planning. Cosmos Taxis 1 (3): 10-19.

Jacobs, J. 1961. Death and Life of Great American Cities. New York: Random House.

Keane, A., and Jones, P. 2020. Planned Cities. In: Rogers, D., Keane, A., Alizadeh, T., and J. Nelson (Eds.) Understanding Urbanism. Singapore: Palgrave Macmillan.

Kelso, J.S., E. Stolk, and J. Portugali. 2016. Self-Organization and Design as a Complementary Pair. In Complexity, Cognition, Urban Planning and Design, ed. J. Portugali and E. Stolk. Berlin: Springer.

Kostof, S. 1991. The City Shaped: Urban Patterns and Meanings Through History. London: Themes and Hudson.

Kropf, K. 2018. Plots, Property and Behaviour. Urban Morphology 22 (1): 5-14.
Lynch, K. 1960. The Image of the City. Cambridge: MIT press.

Kant, I. (1790/2009). The Critique of Judgment. Oxford: Oxford University Press.

Marshall, S. 2009. Cities, Design and Evolution. London: Routledge.

Mehaffy, M.W. 2007. On the Nature of order: An Interview with Christopher Alexander. Urban Design International 12 (1): 51-57.

Moore, J.S. 1942. Beauty as Harmony. The Journal of Aesthetics and Art Criticism 2 (7): 40-42.

Moroni, S., and S. Cozzolino. 2019. Action and the City. Emergence, Complexity, Planning. Cities 90: 42-51.

Moroni, S. and Cozzolino, S. 2020. Actions and Conditions of Actions. Limits and Opportunities of planning in complex social-spatial systems. In: de Roo, Yamu, Zuidema (Eds.) Handbook on Planning and Complexity. Cheltenham: Edward Elgar, pp. 186-202.

Moroni, S., W. Rauws, and S. Cozzolino. 2020. Forms of Self-Organization: Urban Complexity and Planning Implications. Environment and Planning b: Urban Analytics and City Science 47 (2): 220-234. https://doi.org/10.1177/2399808319857721.

Norberg-Schulz, C. 1979. Genius Loci: Towards a Phenomenology of Architecture. New York: Rizzoli.

Noyes, C.E. 1907. The Gate of Appreciation: Studies in the Relation of Art to Life. Mifflin: Houghton.

Sepe, M., and M. Pitt. 2014. The Characters of Place in urban Design. Urban Design International 19 (3): 215-227.

Porqueddu, E. 2018. Toward the Open City: Design and Research for Emergent Urban Systems. Urban Design International. https:// doi.org/10.1057/s41289-018-0065-0.

Porta, S., Romice, O. 2014. Plot-Based Urbanism: Towards TimeConsciousness in Place-Making. In: Dortmunder Vorträge zur Stadtbaukunst [Dortmunder Lectures on Civic Art]: New Civic Art, pp. 82-111.

Porta, S., Y. Rofé, and M. Vidoli. 2016. The City and the Grid: Building Beauty at Large Scale. In A City Is Not a Tree, 50th, Anniversary, ed. M. Mehaffy, 163-184. Portland, OR: Sustasis Press.

Portugali, J. 2016. Complexity, Cognition and the City. Berlin: Springer.

Romano, M. 2008. La città come opera d'arte. Torino: Einaudi.

Taylor, N. 2009. Legibility and Aesthetics in Urban Design. Journal of Urban Design 14 (2): 189-202.

Wohl, S. 2017. From form to Process: Re-conceptualizing Lynch in Light of Complexity Theory. Urban Design International 22 (4): 303-317.

Publisher's Note Springer Nature remains neutral with regard to jurisdictional claims in published maps and institutional affiliations. 